\title{
Analysis on the Key Design and Implementation of Green Public Building
}

Shandong Institute of Architectural Design, Shanghai 200127, China

\section{Introduction}

First, A public building green design evaluation concept

Green building design and construction, with a certain development and implementation of the complexity and systematic, in the design and planning need to be more comprehensive consideration, green building evaluation system consists of the following indicators: energy saving and energy consumption, water saving and water resources consumption, land saving and outdoor environment, materials saving and materials utilization, indoor environmental quality, operation and management. Each category includes controls, general terms and preferences. Green building contains more content, and control content must be met, according to meet the general terms and the number of preferences, and divided into three levels, stars from low to high were: one star, two stars, and three stars in total of 3 levels. 3 levels of green buildings should meet the green building standard control content requirements, and each type of index score should not be less than 40 points. When the green building total score of 50 points, 60 points and 80 minutes, green building grades were divided into one star, two stars and three stars.

Second, Key points of public green building design for public buildings

\section{Project Overview}

1.1 The project is a commercial building in Shanghai, on the ground with 11 units, under- ground for a whole excavation of the basement. 1 \# 9 \# building (all for commercial) for the multi-storey business; 10 \# floor (commercial building) at high of 19 layer, building height of 79.3 meters; 11 \# building (hotel, a total of 214 key room) height 55.7 meters; basement: the ground floor for the garage, equipment area, hotel logistics area, the second floor of the air defense area and civil garage, motor vehicle parking spaces were 473 . The total construction area of the project is about 90,000 square meters.

1.2 The electrical equipment room set up in the project: 10 \# floor in the first floor set $10 \mathrm{KV}$ switch station, in the ground floor of a garage set up three users substation; In the underground garage on the north side, set for the base to use the total network room, cable TV room and telecommunications room; in the garage of the ground floor to set for fire prevention and control room.

\section{Planning and Measures of Green Building Design}

The green building of the project is designed and constructed according to one star standard. As the east side of the project is a natural river, the west side of the city viaduct, planning through the rational layout of the building and the structure and window wall and other active design means to create a good sound, light, wind, heat and other indoor environment. High-rise building roof using solar heat source and ground source heat pump system, low-rise buildings using roof planting green landscape
Abstract: Architectural green design is a kind of guiding design idea which is derived from the development of modern architecture design in our country. In the construction of new technologies and new materials, new technology and equipment, the building energy consumption to a minimum, in order to achieve the construction industry green sustainable development. Based on this, the article discusses the analysis of the public building electrical green design of some of the design and implementation points for reference.

Key words: Green public building; design and implementation

Published online: 15th July, 2017

design, along the project base on both sides of the river planting evergreen shrubs and landscape lawns, to achieve energy conservation and environmental protection at the same time, so that it is the integration of architecture and the environment.

\section{Technical Measures for Green Design of Building Electricity}

3.1 Selection of materials used in the principle of performance indicators

Engineering equipment and materials must have a national test- 
ing center of the test certificate (3C certification); must meet the product-related national standards; all the equipment in the project are in high efficiency, low energy consumption, advanced performance, durable and reliable, which is an electrical device made of green material.

\subsection{Technical measures for equip- ment selection}

3.2.1 Comprehensive consideration of building power supply and distribution systems, electrical lighting, construction equipment, electrical energy saving, measurement and management measures and the use of renewable energy. Reasonable choice of load calculation parameters, the choice of energy-saving equipment, the use of reasonable illumination standards, reduce equipment and line losses. In order to reduce the light pollution of the high-rise building glass curtain window to the nearby elevated road by the use of glass with low reflectivity.

3.2.2 Transformers intended to use SCB11-10/0.4kV, D, yn11 type epoxy cast low loss, low noise, high efficiency, energy saving and flame retardant dry-type transformers. The low-voltage side of the transformer is set up the automatic compensation device of the electrostatic capacitor to improve the power factor of the power supply and distribution system, and the power factor is increased to 0.92 or above in the form of centralized compensation; The reactive power compensation module adopts the three-phase co-compensation and single-phase compensation mode, the single-phase compensation capacity is not less than $30 \sim 40 \%$ of the total compensation capacity; the dynamic reactive power compensation module adopts the thyristor switch to realize dynamic switching; Each compensation unit with an elimination of high harmonics of the reactor, the reactance rate of not less than $12.5 \%$, to suppress the harmonic current.

3.2.3 Three-phase load as much as possible balanced distribution; the floor of the air-conditioning system equipment, water supply and drainage system equipment, elevator control equipment, such as intelligent control methods to facilitate energy conservation.

\subsection{Electric lighting green design}

The lighting design of this project conforms to the relevant requirements such as illumination standard, illumination uniformity, unified glare value, light color, illumination power density (LPD), energy efficiency index and so on stipulated in "Building Lighting Design Standard" GB50034-2013, which design LPD value $(\mathrm{W} / \mathrm{m} 2)$ is based on the target value in the design standard.

3.3.1 The design of lighting to take full advantage of natural light, the selected lamps are high efficiency and energy-saving lamps. To meet the conditions of glare restrictions, the preferred use of high efficiency lamps and open direct lighting, requiring lamps reflector with high reflectance ratio. Underground garage with tube hanging trunking LED lights. Evacuation indicator light using low-power LED light source and other efficient light source, which is a part of the overall street or garden lights intended to use solar energy as lighting energy.

3.3.2 Conference and multi-function hall, hall, public walkways and other places are used on-site manual control and intelligent (infrared sensor, illumination control) control in two ways. The stairwells, equipment, rooms and other independent use of the room are set up local lighting switch control, underground garage using intelligent lighting control system, the hotel room with plug key energy-saving switch. In addition to emergency exit or security needs of the occasion, the room should be off when the lights.

\subsection{Green energy for construction equipment}

3.4.1 Public areas of air-conditioning system equipment, electrical energy-saving measures are: to monitor air conditioning and new air units and other equipment, fan status, air temperature and humidity, underground garage carbon monoxide concentration; control air conditioning and fresh air units and other equipment to start and stop with enthalpy control and variable air speed control.

3.4.2 Electrical and energy saving measures for water supply and drainage system equipment: monitoring the water level and system pressure of water pump and water tank (water tank) of living water supply, central and drainage system, and automatically controlling the start and stop of the corresponding pump according to the water level and pressure state control system main and standby pump start and stop sequence; the system failure, high and low water level and overtime operation to the police.

3.4.3 Electrical equipment, electrical energy saving measures: the selection of energy efficient motor, $30 \mathrm{~kW}$ and above AC asynchronous motor with soft start; fire pump and spray pump to ensure reliable operation should use star delta start control and life pump frequency control.

3.4.5 Electrical energy saving measures for elevator equipment: When more than one elevator is arranged in a centralized manner. It should have the group control function which is centralized and controlled according to the stipulated procedure. The elevator with high efficiency motor and advanced control technology should be used. Device and set the sensor to control the escalator to start and stop, in the full range of sections are no load, which should be able to stay in the pause or low-speed operation.

\subsection{Energy monitoring system}

3.5.1 Energy consumption measurement system should be based on higher-level data center requirements and automatic transmission of energy consumption data. Energy consumption measurement system set up monitoring center. Energy consumption measurement system 
response to water, electricity, gas, central heating, centralized cooling, renewable energy and other types of energy into the line classification and sub-measurement.

3.5.2 High-voltage distribution room outlet and the substation of the low-voltage side of the outlet part of the installation of variable power distribution monitoring system, the system can focus on assessment and monitoring of electricity, is conducive to optimizing and develop effective energy efficiency measures. The monitoring system can achieve "four remote functions", harmonic analysis, report printing, fault alarm, etc. and to achieve power distribution management. Measurement instruments are measured with active and reactive power of the automatic measurement function.

3.6 With substation within the shielding, noise reduction measures

3.6.1 In the wall and the floor laying steel mesh, and connected with the grounding device; or brush shielding paint (conductive paint): silver conductive paint, silver and copper conductive paint, nickel conductive paint.

3.6.2 In the transformer base are installed under the shock absorber; in the substation wall and ceiling installation of special low-frequency noise sound absorption board and other measures to reduce noise.
4 Building Electrical Green Design Evaluation and Management (item)

Strict implementation of the "green building evaluation standards", "public building green design standards" in the sub-item, according to different green building stars, the implementation of the corresponding standards, which mandatory items must be strictly enforced, general terms and preferences according to the project situation to be carried out.

\subsection{Technical requirements for construction management}

Should avoid the material procurement process shoddy and reduce product quality standards. It should be strictly in accordance with the design drawings technical indicators quality standards procurement. Construction process should be standardized construction, do not cheat in work and cut down on materials and instead improve the quality of construction. Energy consumption metering system should be synchronized with the building design, construction and acceptance of the work.

\subsection{Technical requirements for op- erational management}

The implementation of energy consumption classification, sub-user measurement fees, and a complete record and analysis. On the building lighting, air conditioning, water supply and drainage, elevators and other monitoring points to run the monitor- ing.

For the individual office, commercial buildings according to different types of rental households, the power consumption, cold and heat, etc. by the classification of property classification fees.

\section{Fourth, Conclusion}

To create a low-carbon green office environment to enhance the utilization of resources, because the project is on the left side of the city is building a highway fast road, the project must be strictly controlled light pollution and glare value, so as to avoid causing pollution to the surrounding roads. The use of the surrounding landscape river and landscape vegetation to create a green office shopping environment which is a great improvement of comfort.

\section{References:}

[1] Public Building Green Design Standards DGJ08-2143-2014. Tongji University Press, 2014, Shanghai

[2] Green Building Evaluation Standards GB / T50378-2014. China Construction Industry Press, 2014

[3] Energy Efficiency Design Standard for Public Buildings DGJ08107-2012. China Construction Industry Press, 2012 